AperTO - Archivio Istituzionale Open Access dell'Università di Torino

\title{
Labor policies and capital mobility in theory and in EMU
}

\section{This is the author's manuscript}

Original Citation:

Availability:

This version is available http://hdl.handle.net/2318/1564573

since 2016-06-07T09:36:38Z

Published version:

DOI:10.1016/j.euroecorev.2016.04.007

Terms of use:

Open Access

Anyone can freely access the full text of works made available as "Open Access". Works made available under a Creative Commons license can be used according to the terms and conditions of said license. Use of all other works requires consent of the right holder (author or publisher) if not exempted from copyright protection by the applicable law. 


\title{
Labor policies and capital mobility in theory and in EMU
}

\author{
Giuseppe Bertola * \\ 2016 forthcoming, European Economic Review
}

\begin{abstract}
Europe's Economic and Monetary Union (EMU) was characterized by large international imbalances and uneven national labor market reforms. In this paper's model, labor policies that aim to increase the welfare of capital-poor individuals within each country are influenced by financial integration across differently capital-abundant countries. The model predicts that capital outflows should be associated with labor market deregulation, as was the case in EMU, and helps interpret inequality developments and policy tensions in that experience.
\end{abstract}

* Very useful comments on earlier drafts are gratefully acknowledged to three referees and to workshop and seminar participants at CREST (Paris), CEGE (Goettingen), ESt (Turin), EDHEC (Nice), University of Bonn, and ECB - DG Research.

JEL: F2, J08

Keywords: Policy competition, Politico-economic equilibrium. 


\section{Introduction}

Labor market policies, rooted in country-specific historical factors and political compromises, continue to be determined at the National level within the European Union's increasingly integrated economic system. The resulting policy competition (Sinn, 2003) and "race-to-thebottom" deregulation may be disturbing for those who value social policy's objectives, or welcome for those who resent Leviathan governments and think existing policies are wasteful and misguided. In any case, this theoretically obvious mechanism is empirically visible in Europe's Economic and Monetary Union (EMU), where the tighter economic integration implied by adoption of a single currency was empirically associated with labor market deregulation as well as with lower social policy expenditure and growing inequality of disposable incomes (Bertola 2010a,b).

It is more interesting to note that the intensity of labor market reforms was different across EMU member countries, and related to international capital flows. In the early 2000s not only did Germany stand out as much by its large current account surpluses as by its labor market reforms (Rinne and Zimmermann, 2012), but capital outflows and labor market reforms were more generally related across EMU member countries. Figure 1 plots current accounts and the European Commission's Directorate General for Economic and Financial Affairs and Economic Policy Committee LABREF database of country-specific reforms, summarized as in Turrini et al. (2015) by the cumulative country-specific count of measures deemed to be increasing labor market flexibility, net of those deemed to decrease it. ${ }^{1}$ These data show that labor market deregulation and current account deficits were positively and significantly related across countries between 1998 (the first year available in the LABREF database and the last before EMU) and 2005, 2006, or 2007 (the choice between these three dates matters little because most of the divergence from zero of the two indicators had occurred by 2005, but a positive time-series association is still visible over the $2005-2007$ period in Greece, Spain,

\footnotetext{
${ }^{1}$ The summary indicator includes reforms of "Job Protection (EPL)", "Labour Taxation", "Unemployment benefits", "Wage Setting", "Working Time", "Other welfare-related benefits".

The database, available at http://ec.europa.eu/economy_finance/db_indicators/labref/index_en.htm, also covers reforms of "Active labour market policies", "Early Withdrawal", "Immigration/Mobility", and "Pensions".
} 
and Ireland).

\section{Figure 1}

One might want to interpret the evidence as a causal relationship running from exogenous reforms to current account imbalances. For some reason, certain countries chose to increase the rigidity of their labor markets, lost competitiveness, and spent in excess of their income. A feeling that such behavior was misguided might be strengthened in some eyes by the fact that it was severely punished by a crisis which spared the more virtuous countries, in the topright quadrant of Figure 1, that deregulated their labor markets, restrained their expenditure, and also happened to record the best European performances in the 2014 World Cup.

This paper adopts a less moralistic perspective on labor policies in the aftermath of financial integration. Because higher capital intensity benefits individuals whose income disproportionately accrues from labor, policy boosts wages and reduces employment in economies where politically decisive individuals are capital-poorer than the average individual. If it becomes possible for capital to flow across the borders of the countries choosing such policies, the politico-economic equilibrium swings towards deregulation more strongly in relatively capital-abundant ones, where politically decisive individuals become less capital-poor in the integrated market than they were in autarky. To the extent that realized capital flows reveal

the relative capital intensity of countries, the model can explain the pattern seen in Figure 1.

This reasoning builds on insights from models of economic integration's distributional implications for countries with different factor endowments (Mayer, 1984) and from the international tax competition literature (reviewed by Keen and Konrad, 2013). Its focus on the labor policy implications of financial integration, and its ability to explain the covariation of reforms and international financial flows, are novel but related to previous theoretical and empirical studies of interactions between economic integration and labor markets. Because more intense product market competition increases the elasticity of labor demand, even in the absence of capital or labor mobility economic integration reduces the appeal of policies that reduce production efficiency in order to insure or redistribute incomes (e.g. Bertola and 
Boeri, 2002). This effect is plausibly stronger when adoption of a single currency improves price transparency and removes devaluation risk. While country-specific information might bring this partial-equilibrium insight to bear on heterogeneous reform patterns within EMU, it appears difficult to establish empirical proxies for the strength of international productmarket linkages. A different strand of literature uses models of aggregate demand and supply fluctuations to focus on interactions between monetary unification and labor market institutions that shape and coordinate employment and wage responses to shocks and monetary policy (Sibert and Sutherland, 2000; Bentolila and Saint-Paul, 2001; Calmfors, 2001a,b). From this perspective EMU membership might reduce deregulation incentives, by delivering low inflation even to countries where highly regulated and poorly coordinated labor markets would bias inflation upwards (Calmfors, 2001a). This theoretical possibility is not empirically confirmed by evidence of average deregulation in EMU (Bertola 2010b) and of monetary policy credibility's association with structural deregulation in broader advanced country samples (Belke, Herz, and Vogel, 2007). Predictions that EMU would foster wage restraint in traditionally low-credibility countries such as Italy and perhaps Finland (Calmfors, 2001b) are also hard to validate with the short time series data available to assess such patterns across EMU countries.

The paper derives its simple points in Sections 2 and 3, introducing and interpreting labor market policy in an economy where individuals differ in terms of whether their income is earned by labor or from capital, and characterizing the impact in this context of capital mobility across the boundaries of labor policy enforcement areas. Section 4 offers additional evidence, assessing the extent to which the relationship between labor market reforms and international imbalances is specific to early EMU experience, measuring reforms in terms of quantitative policy indicators as well as of the LABREF count indicator, and checking whether uneven reform patterns might alternatively be explained by convergence from initially different configurations to the deregulated "bottom" or to some uniform level and style of regulation. Section 5 studies the model's welfare implications and notes that under plausible conditions capital mobility should in theory, and did in EMU, increase income inequality 
within capital-abundant countries. Section 6 concludes discussing the implications for current policy debates of the pre-crisis empirical evidence analyzed in this paper and of the proposed theoretical interpretation.

\section{Labor policy}

Consider an economy where two factors, capital and labor, enter a constant returns production function with total productivity $a$ and (for simplicity) constant elasticity: $n l$ units of labor and $k$ units of capital produce $k^{\alpha}(a n l)^{1-\alpha}=(\kappa)^{\alpha}$ anl units of output, where $\kappa \equiv k /($ anl $)$ denotes the economy's capital intensity. Output is paid to factor units according to their marginal productivity,

$$
w=a(1-\alpha)(\kappa)^{\alpha}, r=\alpha(\kappa)^{\alpha-1}
$$

which is increasing in capital intensity for labor, and decreasing for capital.

The economy is populated by individuals indexed by $i$ who own heterogeneous amounts $k_{i}$ and $n_{i}$ of the two factors. Crucially, labor supply is endogenous, in that individuals choose the proportion $l_{i}$ of their $n_{i}$ that is employed in market production. Using a constant elasticity function to represent its income-equivalent welfare cost, individual $i$ 's total welfare has the quasilinear form ${ }^{2}$

$$
u_{i}=r k_{i}+w n_{i} l_{i}-b \frac{\left(l_{i}\right)^{1+\beta}}{1+\beta} n_{i}
$$

It will be of interest to characterize the individual welfare implications of policies that, as discussed in the next subsection, insert a proportional wedge $\omega \neq 1$ between the marginal product of labor, $w$ in (1), and the income-equivalent marginal utility of non-market activities, $b\left(l_{i}\right)^{\beta}$. When (2) is maximized with respect to $l$, the first-order condition $b\left(l_{i}\right)^{\beta}=\omega w$ and (1) imply $l=\left(\omega \frac{a}{b}(1-\alpha)(\kappa)^{\alpha}\right)^{1 / \beta}$. Inserting this expression in (2) makes it possible to express individual welfare as a function of $\omega$, aggregate capital intensity, and individual

\footnotetext{
${ }^{2}$ In this simple expression a larger $n_{i}$ increases both market and non-market labor, as may be appropriate if, for example, better education or health not only improve market productivity but also makes leisure more enjoyable. The model would be only slightly more complicated if $b$ were allowed to vary across individuals.
} 
factor endowments:

$$
u\left(\omega, \kappa ; k_{i}, n_{i}\right)=\alpha(\kappa)^{\alpha-1} k_{i}+(1-\alpha)^{\frac{1+\beta}{\beta}}(\kappa)^{\alpha \frac{1+\beta}{\beta}} \omega^{\frac{1}{\beta}}\left(\frac{1+\beta-\omega}{1+\beta}\right)(a / b)^{1 / \beta} a n_{i} .
$$

Because higher capital intensity reduces the unit income of capital and increases the welfare surplus afforded by optimal allocation to market use of labor units, the two additive terms of (3), weighted by the individual's factor endowments, move in opposite directions as $\kappa$ varies at given $\omega$. In turn, the equilibrium $\kappa \equiv k /($ anl $)$ depends on $\omega$ : using $l=(\omega w / b)^{1 / \beta}$ and $w$ from $(1), \kappa=k /\left(\right.$ an $\left.\left(\omega \frac{a}{b}(1-\alpha)(\kappa)^{\alpha}\right)^{1 / \beta}\right)$ can be solved for

$$
\kappa(\omega)=(1-\alpha)^{-\frac{1}{\alpha+\beta}}\left(\frac{k}{(a \omega / b)^{1 / \beta} a n}\right)^{\frac{\beta}{\alpha+\beta}} .
$$

Differentiating $u\left(\omega, \kappa(\omega) ; k_{i}, n_{i}\right)$ with respect to $\omega$, the first-order condition for maximization of $(3)$ can be rearranged to

$$
\alpha(1-\alpha)^{-\frac{1}{\beta}}(\kappa)^{-\frac{\alpha+\beta}{\beta}} \frac{k_{i}}{(a \omega / b)^{1 / \beta} a n_{i}} \eta_{\kappa \omega}=\frac{\alpha}{\beta}(1+\beta-\omega) \eta_{\kappa \omega}+\frac{1}{\beta}(1-\omega),
$$

where $\eta_{\kappa \omega} \equiv \frac{\omega}{\kappa} \frac{\partial \kappa}{\partial \omega}=-1 /(\alpha+\beta)$. Inserting (4) in (5), the welfare-maximizing policy parameter is

$$
\omega^{*}=1+\alpha\left(\frac{k_{i} / n_{i}}{k / n}-1\right)
$$

for an individual who earns income from $k_{i}$ and $n_{i}$ in an economy where the aggregate amount of these factors are $k$ and $n$.

\subsection{Interpretation and implementation}

The simple expression (6) shows that $\omega=1$ maximizes the welfare of an individual who owns the two factors in the same proportions as the aggregate economy. Intuitively, efficient laissez faire is what should be observed if the economy admitted a representative individual, either because all individuals are indeed identical, or because public schemes or private contracts make it possible to transfer utility across individuals.

To see why non-representative individuals prefer $\omega \neq 1$, consider the equilibrium implications of preventing equality between labor's marginal market productivity and contribution to 
individual welfare. Figure 2 illustrates a situation where $\omega<1$ increases the market income $w$ of labor and decreases its market employment $l$. Parameters $a, b, k$, and $n$, which determine the scale of aggregate and individual production and employment, are all normalized to unity. Elasticities are set to $\alpha=0.35$ (for roughly realistic factor shares of aggregate income) and $\beta=2$ (this parameter determines the slope of labor supply and distributes policy effects across employment and wage levels, but the model's other implications are the same as long as it is positive and finite). ${ }^{3}$ In the $\omega=1$ laissez faire case these parameters would imply that $l=0.84$. This is the horizontal position of the crossing point of lines tracing tracing employment's marginal implications for a labor unit's market production $(k)^{\alpha}(a l)^{1-\alpha}$ and welfare loss $b(l)^{1+\beta} /(1+\beta)$ in Figure 2 , where $\omega=0.825$ lowers $l$ by $0.175 /(\alpha+\beta)=0.074$, or about $9 \%$, below it laissez faire level.

\section{Figure 2}

When $b(l)^{\beta}=\omega w$, the area (around point A in Figure 2) between the downward sloping line and the horizontal line at level $w$ corresponds to the market production of a unit of labor, net of its cost $w l$ : this, scaled by $n / k$, is paid out to capital in equilibrium. The area (around point $\mathrm{C}$ ) between the upward sloping line and the horizontal line at level $\omega w$ corresponds to a labor unit's income $w l$, net of the $b(l)^{1+\beta} /(1+\beta)$ term that represents in a simple and very tractable way the contribution to individual welfare of home production or leisure and, in equilibrium, varies with $l$ and $\omega$ as long as $\beta<\infty$.

Besides areas $\mathrm{A}$ and $\mathrm{C}$, employment $l$ of a unit of labor also yields the welfare corresponding the rectangular area around point B. This can be shifted toward labor by policies that have the effects of $\omega \neq 1$ in the model. ${ }^{4}$ For example, a proportional payroll tax $\tau$ implies $\omega=1-\tau$ : if its revenue (the rectangular area $\mathrm{C}$ in Figure 2) is rebated to individuals in proportion to their $n_{i}$, individual welfare amounts to (3). If labor's marginal productivity

\footnotetext{
${ }^{3}$ Constant-elasticity functional forms imply that factor shares of market income are independent of $\omega$. In the model, capital and labor differ only in terms of international mobility; it would be possible to derive similar theoretical implications allowing for other immobile-factor income, such as that paid to land, and for some internationally mobile labor.

${ }^{4}$ In micro-founded macroeconomic models, policies and deviations from perfect competition can generally be represented by wedges between demand and supply (Chari, Kehoe, and McGrattan, 2007).
} 
cannot decline below $w$, then in Figure 2 labor's unit welfare includes the area around point $\mathrm{C}$ as well as the rectangle around B, and the effects of legal or collectively bargained minimum wages are also represented by $\omega<1$ : it would be individually optimal to supply more labor, but (3) correctly measures individual welfare if involuntary unemployment is evenly spread across all labor units (e.g. because of a minimum wage rate per hour worked), or smoothed across workers by employment lotteries (Andolfatto, 1996, and Merz, 1995), or distributed over the life-cycle of each individual worker. In the model, and in Figure $2, \omega<1$ can also represent such quantity constraints as limits on weekly work hours, minimum annual holidays, or age-related employability rules: in this interpretation, the vertical dashed line in the figure identifies on the horizontal axis a policy-determined market employment level $l$ that is only a proportion $\omega^{1 / \beta}$ of what it would be in laissez faire.

The implications of these policies in isolation, or combined to let wage minima interact with unemployment insurance (UI) benefits funded by payroll taxes, are qualitatively similar to those of $\omega<1$ in the model. In Figure 2, the total welfare $\mathrm{A}+\mathrm{B}+\mathrm{C}$ generated by a unit of labor would obviously be maximized if $\omega=1$ eliminated the rectangle $B$ and the adjoining deadweight triangle. Starting from that laissez faire point, however, even as a smaller $l$ entails a second-order reduction of total surplus an individual who owns relatively little capital benefits to first order by a larger area $\mathrm{B}$, because if $n_{i} / n>k_{i} / k$ then area $\mathrm{A}$ (which amounts to $1 / n^{t h}$ of the economy's total capital income $r k$ ) matters less than the labor-surplus areas B and C in the welfare expression (2). For this reason, that capital-poor individual prefers some $\omega<1$ which, under the model's constant-elasticity assumptions, is readily computed to be $(6)$.

\subsection{Policy determination}

Just as in partial equilibrium a monopoly union restricts employment in order to capture a larger portion of a smaller producer surplus, so policy in the model's simple general equilibrium may decrease total income and welfare in order to redistribute it across heterogeneous individuals. 
Observed policies are those preferred by the politically decisive subset of the population. Recalling expression (6) for each individual's preferred $\omega$, political aspects can be summarized by

$$
x \equiv \frac{\tilde{k}_{i} / \tilde{n}_{i}}{k / n}
$$

for $\tilde{k}_{i} / \tilde{n}_{i}$ is the capital/labor ratio of the decisive individual in an economy where that ratio is $k / n$. In politico-economic equilibrium, policy maximizes that individual's welfare: using (6)

$$
\omega^{*}(x)=1+\alpha(x-1)
$$

implies that the ratio of labor's marginal contributions to welfare in market and non-market uses deviates from unity by the product of $\alpha$, the elasticity to capital of market production, and the deviation from unity of $x$, the decisive individual's capital/labor ratio as a fraction of the economy's. In Figure 2, $x=0.5$, and $\omega=0.825$ maximizes the welfare of an individual who is only half as well endowed with capital as the aggregate economy.

Should the decisive individual's relative capital ratio exceed unity, then $x>1$ would imply that wages are subsidized and leisure is taxed, or that maximum wages and minimum working times are imposed, to move the economy's equilibrium beyond the crossing point in Figure 2. Such policies seem unusual even for the most business-friendly countries. In reality, labor income is taxed and non-employment is subsidized, collective contracts or laws impose minimum wages, and laws set upper bounds on working time. In other models, these as well as more "active" policies might be justified by market failures. In the stylized model of this section, they benefit the individuals who have the power to implement and enforce them: policy distorts employment below its laissez faire level for the purpose of maximizing the welfare of an individual whose capital/labor ratio is smaller than the aggregate one. This simple interpretation is theoretically sound as long as utility can only be transferred across individuals via distorted market interactions and, as will be clear in what follows, fits the empirical evidence well. 


\section{Capital mobility}

Representing the implications of diverse labor policies with a single labor wedge $\omega$ makes it easy to characterize how their politico-economic determination reacts to integration of economies that, like individuals, feature different capital/labor ratios. Labor policy tends to reduce employment if policy is chosen by democratic majority and the median capital/labor ratio is realistically lower than the average. Political power may be unevenly distributed along the relevant dimension of heterogeneity, for example because of wealthier individuals' control of the media. However, any political mechanism that maps heterogeneous economic interests into a choice of $\omega$ can be represented in what follows by an $x$ factor ratio that remains unchanged when a country integrates economically with others, while retaining its power to set and enforce labor policies.

To model economic integration, let capital become mobile beyond the borders of the single-good economy outlined in Section $2 .^{5}$ It is simplest to let the country introduced above integrate with just one other country, where capital and labor amount to $K$ and $N$ rather than $k$ and $n$, and the labor policy wedge is also denoted by an upper case $\Omega$ rather than by $\omega$. Within the integrated economy, countries are entities that set and enforce policy, so their boundaries need not be related to tastes and technology. This makes it sensible to assume constant returns to scale in production and let the elasticity parameters $\alpha$ and $\beta$ be the same throughout the integrated economy. It can however be useful to let the productivity of market and non-market activities be different across countries: $a \neq A$ and $b \neq B$ may represent the productivity implications of policies other than those represented by $\omega$ and $\Omega$, or heterogeneous cultural or geographical features of areas where different policies are enforced.

\footnotetext{
${ }^{5}$ In more detailed models international capital mobility could be redundant because its allocation across sectors with different factor intensities ensures factor-price equalization as in Mayer (1984). It would also be possible to study model economies where differently skilled labor types are more intensively employed in tradable sectors of the integrating economies and/or find it easier to migrate. These adjustment mechanisms may not be as immediate as changes of investment volumes, however, and are not relevant to the early EMU international financial imbalances that motivate this paper.
} 
Under perfect capital mobility, capital intensity is equalized at

$$
\kappa=\frac{k_{d}}{a n l}=\frac{K_{d}}{A N L}=\frac{k+K}{a n l+A N L},
$$

where $k_{d}$ and $K_{d}=(K+k)-k_{d}$ denote the capital amounts used in the two countries' domestic production. Using $l=\left(\omega \frac{a}{b}(1-\alpha)(\kappa)^{\alpha}\right)^{1 / \beta}$ and $L=\left(\Omega \frac{A}{B}(1-\alpha)(\kappa)^{\alpha}\right)^{1 / \beta}$,

$$
\kappa=\frac{k+K}{\left(a n\left(\omega \frac{a}{b}\right)^{1 / \beta}+A N\left(\Omega \frac{A}{B}\right)^{1 / \beta}\right)(1-\alpha)^{1 / \beta}(\kappa)^{\frac{\alpha}{\beta}}}
$$

can be solved for

$$
\kappa(\omega)=(1-\alpha)^{-\frac{1}{\alpha+\beta}}\left(\frac{k+K}{(a \omega / b)^{1 / \beta} a n+(A \Omega / B)^{1 / \beta} A N}\right)^{\frac{\beta}{\alpha+\beta}} .
$$

This equilibrium capital intensity expression is well-defined if $\beta>0$ makes it possible to obtain an interior equilibrium allocation of capital. Like its (4) closed-economy counterpart (which is well defined in the $\beta=0$ case of constant returns to $k$ and $n$ ), it depends on $\omega$, but capital mobility implies that the other country's factor endowments and policy wedge also matter, and reduces the elasticity of $\kappa(\omega)$ to an extent that depends on the country's relative size:

$$
\eta_{\kappa \omega}=-\frac{\lambda(\omega, \Omega)}{\alpha+\beta}, \text { for } \lambda(\omega, \Omega)=\frac{a n(\omega a / b)^{1 / \beta}}{(a \omega / b)^{1 / \beta} a n+(A \Omega / B)^{1 / \beta} A N} .
$$

Inserting (10) and (9) in (5), the first-order condition for maximization with respect to $\omega$ of the lower-case country's decisive individual's welfare, at given $\Omega$, can be rearranged to

$$
\omega^{*}(x)=1+\alpha\left(\frac{\beta \lambda(\omega, \Omega)}{(1-\lambda(\omega, \Omega)) \alpha+\beta}\right)\left(\frac{k}{K+k} \frac{1}{\lambda(\omega, \Omega)} x-1\right)
$$

where $x$ as in (7) denotes the ratio of the decisive individual's to the country-average factor income sources and, unless migration or electoral reforms modify the country's policy-making framework, is not affected by integration. ${ }^{6}$

\footnotetext{
${ }^{6}$ These derivations and expressions are similar to their closed-economy counterparts, but not as easily illustrated: in a picture like Figure 2's, the downward-sloping demand relationship depends on capital intensity which in turn depends on equilibrium employment $l$ and, through it, on both countries' parameters and policies. This is also the reason why the labor supply slope parameter $\beta$ is policy-irrelevant in the closed-economy version of the model, but does appear in (11).
} 


\subsection{Symmetry and size}

In the integrated economy's equilibrium, the policy parameters $\omega$ and $\Omega$ should simultaneously satisfy (11) and the similar condition

$$
\Omega^{*}(X)=1+\alpha\left(\frac{\beta(1-\lambda(\cdot))}{\lambda(\cdot) \alpha+\beta}\right)\left(\frac{K}{K+k} \frac{1}{1-\lambda(\cdot)} X-1\right)
$$

for the policy-making entity denoted by upper-case variables.

A closed-form solution is available in the special case where countries are fully symmetric. If $K=k, A=a, N=n, B=b$, and $X=x$, then $\lambda=1 / 2=k /(k+K)$, and the policy indicators

$$
\omega=1+\frac{\beta}{\alpha+2 \beta} \alpha(x-1)=\Omega
$$

where $\beta /(\alpha+2 \beta)<1$, are closer to unity than (8). Uncoordinated policy choices gravitate towards the laissez faire $\omega=\Omega=1$ configuration because capital mobility dilutes the incentives for non-representative individuals to distort employment. Formally, the welfare effects of employment distortions work through changes of capital intensity with an elasticity that is only half as large as in autarky for two symmetric integrated countries. Intuitively, a capitalpoor decisive individual still prefers to reduce employment, but to a lesser extent when the resulting higher capital intensity and lower capital unit income induces capital outflows.

Consider next the implications of country size. In models of tax competition, the burden of financing public spending falls on immobile factors (Keen and Konrad, 2013), and relatively small constituencies within an integrated economic area impose lower tax rates because their tax base is more elastic than that of larger ones. Here, country size is measured in terms of the share $\lambda$ of the integrated economy's employment. This, as defined in (10), depends not only on population $n$ and productivity $a$, but also on the policy parameter $\omega$. To satisfy (11), $\omega$ becomes its autarky counterpart (8) as $\lambda$ and $k /(K+k)$ tend to unity, and tends towards its unitary laissez faire value as $\lambda$ and $k /(K+k)$ tend to zero: for a small open economy that integrates in big world, capital intensity is independent of $\omega$, and employment distortions that leave unit factor incomes unchanged are completely pointless. Between these extreme cases, the smaller country enforces less restrictive policies: differentiating the right-hand side 
of (11) with respect to $\lambda$ yields

$$
\frac{d}{d \lambda}\left(1+\frac{\alpha \beta \lambda}{\alpha(1-\lambda)+\beta}\left(\frac{k}{K+k} \frac{1}{\lambda} x-1\right)\right)=-\frac{\alpha \beta}{(\alpha+\beta-\alpha \lambda)^{2}}\left(\alpha\left(1-\frac{k}{K+k} x\right)+\beta\right),
$$

which is certainly negative if $x<1$ implies that labor policy realistically favors relatively capital-poor individuals. Hence, a policy that is enforced over a smaller portion of the integrated economic area implies a smaller deviation of $\omega$ below unity. Country size is in turn a function $\lambda(\omega, \Omega)$ of endogenous policy choices, and combining (14) with

$$
\frac{d \lambda(\omega, \Omega)}{d \Omega}=-\frac{1}{\beta \Omega} \lambda(\omega, \Omega)(1-\lambda(\omega, \Omega))<0
$$

implies an intuitive "race-to-the-bottom" mechanism: deregulation elsewhere decreases the country's effective relative size, and makes deregulation more attractive.

\subsection{Capital asymmetries and flows}

The policy determination condition (11) differs from its autarky counterpart (8) not only because $\beta \lambda(\omega, \Omega)(\alpha(1-\lambda(\omega, \Omega))+\beta)^{-1} \neq 1$, representing familiar policy spillovers, but also because $\lambda(\omega, \Omega) \neq k /(K+k)$, i.e., each country's share of immobile effective labor differs from its share of mobile capital in the integrated economy. While integration of completely symmetric countries just shifts policy from (8) to (13), integration of countries with different capital intensity also triggers capital mobility, and the model's politico-economic mechanism implies different policy choices when integration makes the country's decisive individual more or less capital poor than in autarky. If the (unchanged) decisive individual is less capitalpoor in the integrated economy than in his own country, integration implies labor market deregulation. This is what happens if the country as a whole is relatively capital-abundant, and experiences capital outflows upon integration. In a country that is capital-poor relative to the integrated area and experiences capital inflows, conversely, the model predicts that labor policy should become relatively more restrictive.

Nonlinearity of the $\lambda(\cdot)$ function prevents closed-form solution, but these intuitive results can be illustrated numerically. Consider the implications of integration between the country 
considered in Figure 2 and one of two possible partner countries. In Figure 3, both candidates for integration with Figure 2's "peripheral" country are "core" countries with higher capital endowment $(K=3 k)$ and total productivity $(A=1.1 a$, which prevents full convergence of labor unit incomes). In the top row of panels in Figure $3, N=n$. In the bottom row, $N=0.25 n$ implies that the core country is even more capital-intensive in autarky, and that its size is much smaller.

The parameter sets considered in the two rows of Figure are meant to illustrate some general properties of the model. In each row, three diagrams trace the implications of integration for labor policies, for capital intensity, and for market employment. The derivations above characterize policy before and after a stylized financial integration moment. To help interpret the mechanisms at work in the model, however, each panel of the figure plots three values of the variables on the vertical axis, moving horizontally from autarchy, to integration without reoptimizing $\omega$ and $\Omega$, and finally to the integration with reoptimization ("reform") equilibrium of the model's integrated economy with national labor policies. ${ }^{7}$

\section{Figure 3}

The left-hand panels of Figure 3 show how the intensity of deregulation depends on relative size and capital abundance. Both of the core country examples are more capital intensive and deregulate less than the peripheral country. In the second row, where the peripheral country is relatively large and very capital-poor, its $\omega$ parameter actually declines upon integration, showing that the model can fit Figure 1's evidence of increasing regulation in some EMU countries.

In the other panels of Figure 3, capital flows and changes of employment $l$ equalize the countries' post-integration capital intensity. At unchanged policies, integration-induced capital flows move the wage and $l$ along labor supply relationships, upwards in the periphery and downwards in the core. The rightmost segment in each panel shows the implications of reforms. These are much more modest for capital intensity than those of integration: in the

\footnotetext{
${ }^{7}$ While a situation where capital is already mobile but policies have not yet been reformed resembles Germany's after EMU and before the reforms, characterization of dynamic policy transitions is beyond the scope of this paper, and beyond reach of available data.
} 
examples shown, capital intensity differs by factors of 3 or even 10 in autarky, but reforms change $\omega$ by single-digit percentages; in general, reform asymmetries depend to heterogeneous capital intensity, so the second-round capital intensity implications of reforms are an order of magnitude smaller than the direct implications of intensity-equalizing capital flows.

The countries' reforms and their employment implications, however, are interestingly different both in general and in the specific examples shown in Figure 3. In the core country, deregulation fully or partially offsets the $l$ effect of capital flows. In the top row, the periphery also deregulates and increases employment, so reforms induce a decline of capital intensity in the integrated area. In the bottom row, the relatively large periphery country's decisive agent finds it optimal to move $\omega$ further away from unity, tightening regulation and reducing employment: for the parameters used in plotting the figure, this happens to fully offset deregulation in the core, and reforms leave unchanged the integrated area's capital intensity.

\subsection{Many countries}

The mechanisms illustrated by the two-country example can be readily extended to a larger number of countries. When $N$ countries indexed by $c$ join a common capital market, in each the policy wedge moves from an expression in the form (8) to the solution of a system of $N$ equations in the form (11), with

$$
\kappa=(1-\alpha)^{-\frac{1}{\alpha+\beta}}\left(\frac{\sum_{c=1}^{N} k_{c}}{\sum_{c=1}^{N}\left(a_{c} \omega_{c} / b_{c}\right)^{\frac{1}{\beta}} a_{c} n_{c}}\right)^{\frac{\beta}{\alpha+\beta}} .
$$

Figure 4 illustrates numerically the cross-sectional implications of integration across countries featuring all 27 combinations of a low, a mid-range, and a high value of capital $k_{c}$, population $n_{c}$, and efficiency $a_{c}$. Other parameters, and in particular the relative capital abundance $x$ of decisive individuals, are the same in all countries as in the previous figures. Hence, $\omega_{c}=0.825$ for all countries in autarky. Because for large $N$ uncoordinated policies are enforced in small portions of the integrated area's effective labor, the model predicts that perfect financial integration should everywhere result in almost complete deregulation. Showing how the reforms that bring countries nearly to the deregulated "bottom" are related 
to country-specific parameters and to capital reallocation, however, uncovers patterns that are qualitatively similar to those implied in more complicated models, and in reality, by the less intense policy competition at work when frictions prevent complete return equalization across (and within) countries.

\section{Figure 4}

Three panels of Figure 4 illustrate some ceteris paribus predictions of the model: deregulation pressure is weaker in countries that are larger in terms of the size $n$ and/or efficiency $a$ of their immobile factor endowment, or less capital abundant. The position and slope of the relationship between each of these country features and reforms depends on parameters other than the one on each panel's horizontal axis. At given $k$, for example, larger $n$ or $a$ imply lower deregulation pressure, and smaller intensity-equalizing capital flows. But while country heterogeneity has too many dimensions, even in this simple model, to be reliably detected on the basis of available macroeconomic data, it is interesting and intuitive to see in the bottom-right panel that it is largely smoothed out when the theoretical implications of integration for deregulation and for capital flows are plotted against each other. Almost regardless of the reason why capital intensity differs in autarky, the impacts of integration on capital flows and on reforms are positively related across countries. The resulting association between capital flows and changes of the $\omega_{c}$ labor wedge is similar to the empirical correlation between current accounts and the LABREF count of policy measures shown for EMU in Figure 1.

\section{EMU, not EMU, and policy indicators}

The model's perspective and insights can be relevant in regions and periods other than the early EMU experience that motivates this paper's theoretical exercise. The prediction that at given capital intensities smaller integrated policy-making entities should have stronger incentives to deregulate fits the wage moderation and labor market flexibility implemented by the 1982 Wassenaar agreement in the Netherlands, which at the time was a small portion of a 
completely integrated German economic area, while Germany's labor policy was deregulated only in the mid-2000s, when not only EMU but also EU enlargement made the country small and capital-intensive enough to choose labor market flexibility. Because the financial integration implied by EMU can be timed and bounded more precisely than other events, however, it offers a real-life counterpart to the exogenous removal of barriers to international capital mobility that, in the model, endogenously triggers both capital flows and labor market reforms. To the extent that "downhill" capital flows contributed to external imbalances within EMU (Blanchard and Giavazzi, 2002) as labor policies remained country-specific, the model explains the positive correlation between capital outflows and policy deregulation across countries in Figure 1.

It is interesting to compare that pattern to those observed in other country groups or periods. Over the early EMU period, Figure 5 shows that the correlation of current account imbalances and labor market reforms is weak across the EU member countries that did not adopt the euro. It does become significantly positive when the comparison period extends to 2007, by which time EU enlargement plausibly implied broader forces of the type experienced by EMU members in the early 2000 s.

\section{Figure 5}

The model's insights are also applicable to the period after a crisis which to a large extent severed the international financial linkages introduced by EMU. If capital stops flowing across borders, the model predicts a reversal of the reforms pattern displayed in Figure 1. In Figure 6, the LABREF cumulative reform indicator indeed shows Portugal, Greece, and Spain moving towards labor market flexibility after 2009, and core countries moving in the opposite direction (Germany's introduction of a minimum wage in 2015, not yet tallied in these data, also fits the predicted pattern).

\section{Figure 6}

The patterns shown in Figures 1, 5, and 6 are all very similar if cumulated current accounts are normalized by initial rather than cumulated GDP, by GNP, or by population (except that 
Luxembourg's current account is even more positive on a per capita basis than as a share of GDP or GNP). The LABREF count of reform used in those figures is only available for EU countries, assigns the same weight to more or less drastic changes of different policies, and cannot speak to whether the countries that deregulate the most are those that were initially more regulated, as would be the case if they face stronger "race-to-the-bottom" pressure (though it would be hard to explain on this basis why some countries tighten labor market regulation) or informal coordination mechanisms induce convergence to some uniform level of labor market regulation. ${ }^{8}$ To address these limitations it is possible to inspect for OECD countries rough quantitative indicators of the policies that, as discussed in Section 2.2, may implement the model's labor wedge $\omega$.

Figures 7 and 8 inspect labor tax rates, which correspond to $\omega$ 's deviation from unity in the model, and unemployment insurance replacement rates and social expenditure's income share, both of which may proxy the non-employment subsidies that in the model let a low $\omega$ result in higher worker welfare. These data are of course approximative, available for most non-EU member countries of the OECD but not for all EU countries, and only since 2000 (just for odd-numbered years in the case of UI replacement rates).

The top-left panel of Figure 7 shows a negative and significant relationship between changes of labor tax wedges and current account surpluses across EMU countries. Like Figure 1's evidence, and like the less significant relationship shown in the center panel for unemployment insurance replacement rates, this is consistent with theoretical incentives for stronger deregulation in the capital-abundant countries that experience capital outflows. If changes of social expenditures as a percent of national income are a proxy for regulatory reforms, their correlation with current accounts in the right-hand panel also conforms to the model's predictions. ${ }^{9}$ The corresponding panels in the bottom row of Figure 7 show insignificant relationships across other OECD countries, hence the model's theoretical mechanism

\footnotetext{
${ }^{8}$ The EU Treaties do envision "measures aimed at cooperation, knowledge sharing, and exchanges of information and best practices" for labor and social policy. However, this is only weakly implemented by requiring member states to report on jointly set, verifiable, regularly updated targets (Van Rie and Marx, 2012).

${ }^{9}$ There is instead no relationship between international imbalances and changes of empirical indicators of employment protection, which influences production and redistributes welfare but, unlike the policies discussed in Section 2.2, cannot be represented in terms of a simple labor wedge.
} 
does appear particularly relevant in early EMU experience.

\section{Figure 7}

Quantitative indicators characterize each country's initial policy configuration, so make it possible to assess the extent to which reforms might be explained by simple convergence rather than by the relative capital intensity revealed by current account developments. In Figure 8, initial levels of each indicator are plotted against their changes over the early EMU period. Evidence of the negative relationships that would be implied by convergence is weak across EMU countries, and actually stronger across non-EMU countries. Public social expenditure as a share of income does converge very strongly in both samples, but this may reflects demographic and other structural trends, or mean-reverting cyclical dynamics that, appearing very similar within and outside EMU, offer little empirical support to interactions between labor and monetary policies rather than capital flows.

\section{Figure 8}

In summary, quantitative policy indicators broadly confirm the positive correlation between deregulation and capital outflows implied by the model's politico-economic mechanism, and offer much less convincing support for a simpler convergence-based interpretation of EMU reform patterns.

\section{Integration's inequality implications}

In the model, international economic integration influences not only distribution-motivated labor market policies, but also the distribution of welfare and inequality across and within countries.

Figure 9 shows that, for the numerical example in the bottom row of Figure 3, the lowercase peripheral country enjoys strong GDP growth and increases its labor market's regulation, while the GDP implications of integration are very negative and only partly offset by labor market deregulation in the deregulating upper-case core country. This is similar to Germany's 
experience in EMU, where it "was the largest capital exporter and plunged into a deep slump. Only one-third of its savings was invested at home, the rest being exported. As a result, during the early years of the euro the country had the lowest net investment rate and the lowest growth rate in Europe. Rapidly rising unemployment forced the Schröder government in 2003 to enact painful social reforms" (Hans-Werner Sinn, Financial Times, July 22, 2013). The facts are perfectly consistent with this paper's model, which however explains them in a way that may call for a somewhat different rhetoric.

Before concluding that economic integration damages some countries and benefits others, in fact, one should recognize that welfare depends more on GNP than on GDP. The top-centre panel of Figure 9 shows that GNP grows in both countries, because the same capital outflows that depress GDP in capital-abundant countries make it possible for their capital to earn better returns abroad than it would in autarky. Moreover, if labor supply is endogenous one should also account for the contribution of non-market activities to welfare, measured in the model by expression (2). Its total and average level in each country should generally increase, for two reasons: first, market integration of economies with different factor ratios is welfareimproving for individuals who earn factor incomes in the same proportion as their countries; second, the area-wide labor market deregulation implied by policy competition increases those individuals' welfare, which is maximal at $\omega=\Omega=1$. For the parameterization of Figure 9, the top-right panel shows that integration and reforms end up increasing average welfare by just about the same percentage in the two countries.

Next, it should be noted that sums or averages do not measure country-level welfare when it cannot be transferred across individuals, and that the average change of (2) need not be experienced by any of the model's heterogeneous individuals. To illustrate the model's implications for income and welfare inequality within each of the countries being integrated, the bottom row of panels in Figure 9 displays some relevant indicators for a simple parameterization of within-country heterogeneity. All individuals own one unit of labor but unequal amounts of capital, so that capital income is realistically more unequal than labor income. Fractions $\pi>0.5$ and $\Pi>0.5$ of the population own $\delta k$ and $\Delta K$ units of capital, for $\delta<1$ 
and $\Delta<1$, and the rest own $(1-\delta \pi) k /(1-\pi)$ and $(1-\Delta K) K /(1-\Pi)$ units of capital. So, in each country poor individuals earn a larger proportion of their income from labor, are more numerous than rich ones, and are allowed to democratically choose their country's labor policy.

\section{Figure 9}

For the parameterized example, the bottom-left panel of Figure 9 shows in terms of high/low income ratios that, because economic integration benefits owners of factors that in autarky were relatively abundant, income inequality increases in the core country, where rich individuals can take advantage of better unit incomes and the wage implications of capital outflows disproportionately reduce the income of poor individuals. Inequality declines for symmetric reasons in the peripheral country, and in both countries the much smaller capital intensity and employment effects of reforms partly offset those of capital flows. The center and right panels of the figure's bottom row shows that integration decreases the welfare of rich individuals in the peripheral country and of poor individuals in the core country, and that reforms have further and milder welfare implications: because they increase employment, decrease capital intensity, and increase unit capital incomes at the area-wide level, integration-induced labor policy changes damage individuals who are capital-poor relative to the integrated economy. Some such individuals may of course exist in all countries. In the numerical example, however, reforms as such are not painful for anybody in the core country, because even its capital-poor residents are capital-rich relative to the integrated area.

Capital reallocation has qualitatively similar income inequality implications if capital is distributed across more than two classes of individuals, as long as labor income is less unequal than capital income: capital income convergence implies a positive relationship between capital outflows and within-country inequality changes. In theory, both are endogenous consequences of financial integration. Empirically, Figure 10 shows that across EMU countries cumulated current accounts were indeed positively and significantly related to changes of the Gini coefficient of disposable income inequality. ${ }^{10}$

\footnotetext{
${ }^{10}$ The pattern is very similar in terms of income quintile ratios. The same change of measurement methods
} 


\section{Figure 10}

Labor policy reforms are another endogenous consequence of financial integration. Their impact on measured inequality is not as clear-cut as that of changes of capital intensity. In the model outlined above, the labor share of market income is constant and proportional personal income inequality does not depend on the wedge $\omega$, which influences welfare through changes of employment as well as of unit factor incomes. In reality, the post-tax-and-transfer indicators shown in the figures may be directly influenced by reforms of policies that smooth idiosyncratic risk (Bertola, 2014), and income inequality is also influenced by earnings dispersion, which economic integration may affect through trade of differently skill-intensive goods. As shown in Figure 11, however, EMU labor market reforms do not appear to explain the portion of inequality changes that is not explained by international imbalances. Absence of a systematic relationship does not deny that specific reforms may matter, and Germany's strong deregulation does appear to have contributed to increasing inequality, especially between 2005 and 2007.

\section{Figure 11}

\section{Concluding comments}

The model's politico-economic mechanism explains both capital flows and reforms as endogenous consequences of integration, but cannot explain integration itself as a policy choice. While the implications for labor policy of international economic integration might be one reason for technocrats and wealthy individuals to view the single currency more favorably than the general population, the locally capital-poor individuals who choose labor policies are damaged by capital outflows in capital-abundant "core" countries, and should oppose integration. They may not be in a position to influence their country's international policy, or may favor integration for reasons not included in the model's welfare function. To make integration politically acceptable the model could be extended to account for various economic reasons why it can be generally beneficial, such as the price transparency afforded by was implemented in all countries between 1999 and 2005 (see Bertola 2010a). 
a common currency, or gains from intra-industry trade and economies of scale. There can also be excellent non-economic reasons for democratic acceptance of economic integration. In core countries, the decisive individual's welfare may decrease because of capital outflows and deregulation less than it increases if German reunification and prospective peace are tied to adoption of a single currency. Just because integration is driven also by such political objectives, in fact, the EMU evidence that motivates and supports this paper's analysis offers a rare opportunity to observe the implications of financial integration in a situation where other economic factors play a relatively small role and labor policies remained independent across countries.

This paper's approach and results are positive, not normative, and certainly do not support a view that all EMU countries should follow the example of the virtuous, flexible, and competitive core, or that the periphery should be blamed for negative imbalances resulting from an overpaid, misallocated, and lazy workforce. In EMU, some countries did export more than they imported, and their competitiveness was boosted by wage moderation and labor market flexibility. If financial integration triggers both capital flows and reforms, however, current account deficits are just as natural for capital-poor countries as uncoordinated labor market deregulation is for capital-rich countries. Deviations from the model's predicted pattern may deserve attention in further work. France, Italy, and Germany (all large countries with capital intensities similar to the EMU average) followed interestingly different labor policy trajectories: the LABREF summary indicator shows Italy tightening labor market regulation in the early EMU period and relaxing it after the crisis, while France displays a reform propensity that (like the country's external balances) is similar to Germany's in both periods but is not accompanied by increasing inequality. Such policy and outcome trajectories were presumably driven by shifts in political sentiment, policy details, or structural changes. They cannot be explained by this paper's theoretical perspective, which instead does suggest a possible reason why core governments may insist that crisis countries should deregulate their labor markets: the political representatives of a capital abundant country would like labor markets to be deregulated not only in their own country, but in all of the 
integrated economic area.

The model and the evidence do suggest that labor policy coordination should be more prominent in the design of Europe's policy framework. In EMU, there are binding supranational constraints on competition and state aid regulation but distribution-motivated labor and social policies, always difficult to discuss and often impossible to agree upon, are chosen at the same National level of most political interactions. Yet, in crisis countries they have been strongly influenced by supranational institutions as a condition of financial assistance. It remains to be seen whether the current situation will evolve towards a reversal of previous European economic integration trends, or towards policy coordination. 


\section{References}

Andolfatto, David (1996) "Business Cycles and Labor Market Search" American Economic Review 86 (1): 112-132.

Belke, Ansgar, Bernhard Herz, and Lukas Vogel (2007) "Reforms, Exchange Rates and Monetary Commitment: A Panel Analysis for OECD Countries" Open Economies Review $18369-388$.

Bertola, Giuseppe (2010a) "Inequality, Integration, and Policy: Issues and evidence from EMU" Journal of Income Inequality 8 345-365.

Bertola, Giuseppe (2010b) "Labour Markets in EMU: What has changed and what needs to change" in M.Buti, S.Deroose, V.Gaspar, J. Nogueira Martins (eds.), The Euro: The First Decade, Cambridge UK and New York: Cambridge University Press, 715-758.

Bertola, Giuseppe (2014) "Labor Market Policies and European Crises" IZA Journal of Labor Policy 3:5.

Bertola, Giuseppe, and Tito Boeri (2002) "EMU Labour Markets Two Years On: Microeconomic Tensions and Institutional Evolution" in Marco Buti and Andre Sapir (eds.), EMU and Economic Policy in Europe, Cheltenham UK - Northampton MA: Edward Elgar, 249-280.

Blanchard, Olivier and Francesco Giavazzi (2002) "Current Account Deficits in the Euro Area: The End of the Feldstein-Horioka Puzzle?" Brookings Papers on Economic Activity, 2:2002 147-186.

Calmfors, Lars (2001a) "Unemployment, labour-market reform and monetary union" Journal of. Labor Economics 19(2), 265-89.

Calmfors, Lars (2001b) "Wages and Wage-Bargaining Institutions in the EMU - A Survey of the Issues" Empirica 28(4): 325-351. 
Chari, V. V., Patrick J. Kehoe, and Ellen R. McGrattan (2007) "Business Cycle Accounting" Econometrica 75:3, 781-836.

Keen, Michael, and Kai A. Konrad (2013) "The theory of international tax competition and coordination" in A.J.Auerbach, R. Chetty, M.Feldstein, and E. Saez (eds.), Handbook of Public Economics Volume 5, Amsterdam and Oxford: Elsevier, 257-328.

Mayer, Wolfgang (1984) "Endogenous Tariff Formation" American Economic Review 74:5 970-985.

Merz, Monika (1995) "Search in the Labor Market and the Real Business Cycle" Journal of Monetary Economics 36 (2): 269-300.

Rinne, Ulf, and Klaus F. Zimmermann (2012) "Another Economic Miracle? The German labor market and the Great Recession" IZA Journal of Labor Policy 1:3.

Saint-Paul, Gilles and Samuel Bentolila (2001) "Will EMU Increase Eurosclerosis?" in Charles Wyplosz (ed.), The Impact of EMU on Europe and the Developing Countries, Oxford and New York: Oxford University Press, 128-168.

Sibert, Anne C., and Alan Sutherland (2000) "Monetary Union and Labour Market Reform" Journal of International Economics, 51.

Sinn, Hans-Werner (2003) The New Systems Competition, Oxford: Basil Blackwell.

Turrini, Alessandro, Gabor Koltay, Fabiana Pierini, Clarisse Goffard and Aron Kiss (2015) "A Decade of Labour Market Reforms in the EU: Insights from the LABREF database" IZA Journal of Labor Policy 4:12.

Van Rie, Tim and Ive Marx (2012) "The European Union at Work? The European Employment Strategy from Crisis to Crisis" Journal of Common Market Studies 50:2, 335-356. 


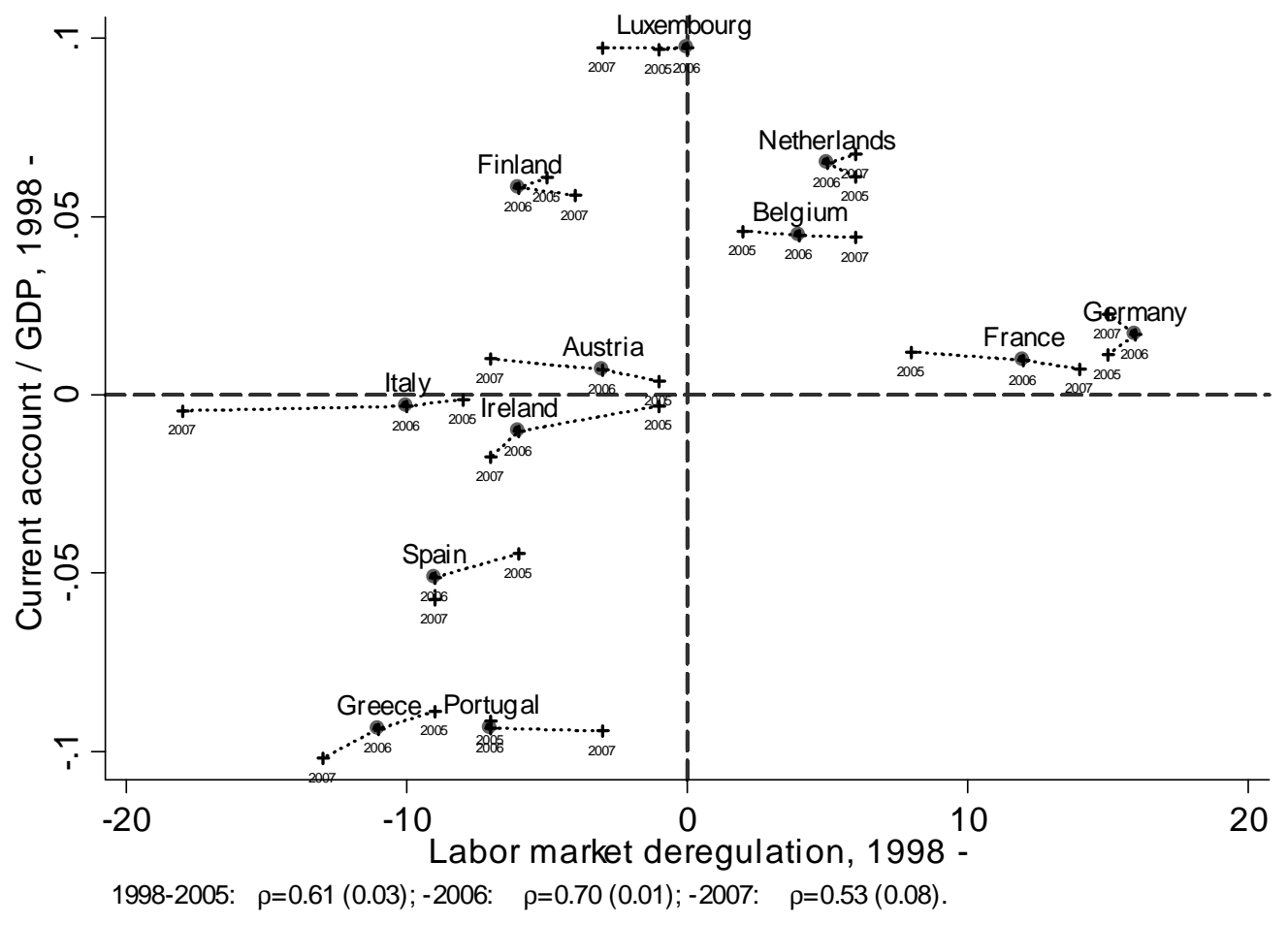

Figure 1. International imbalances and labor market reforms in early EMU.

Rank correlation statistics and the p-value at which they reject the null of independence are reported at the bottom. Data definitions (sources): Cumulative Current Account balance/cumulative GDP (DG EcFin AMECO database); count of measures labeled "Decreasing" net of measures labeled "Increasing" adopted in the period for the domains listed in footnote 1 (DG EcFin LABREF database). 


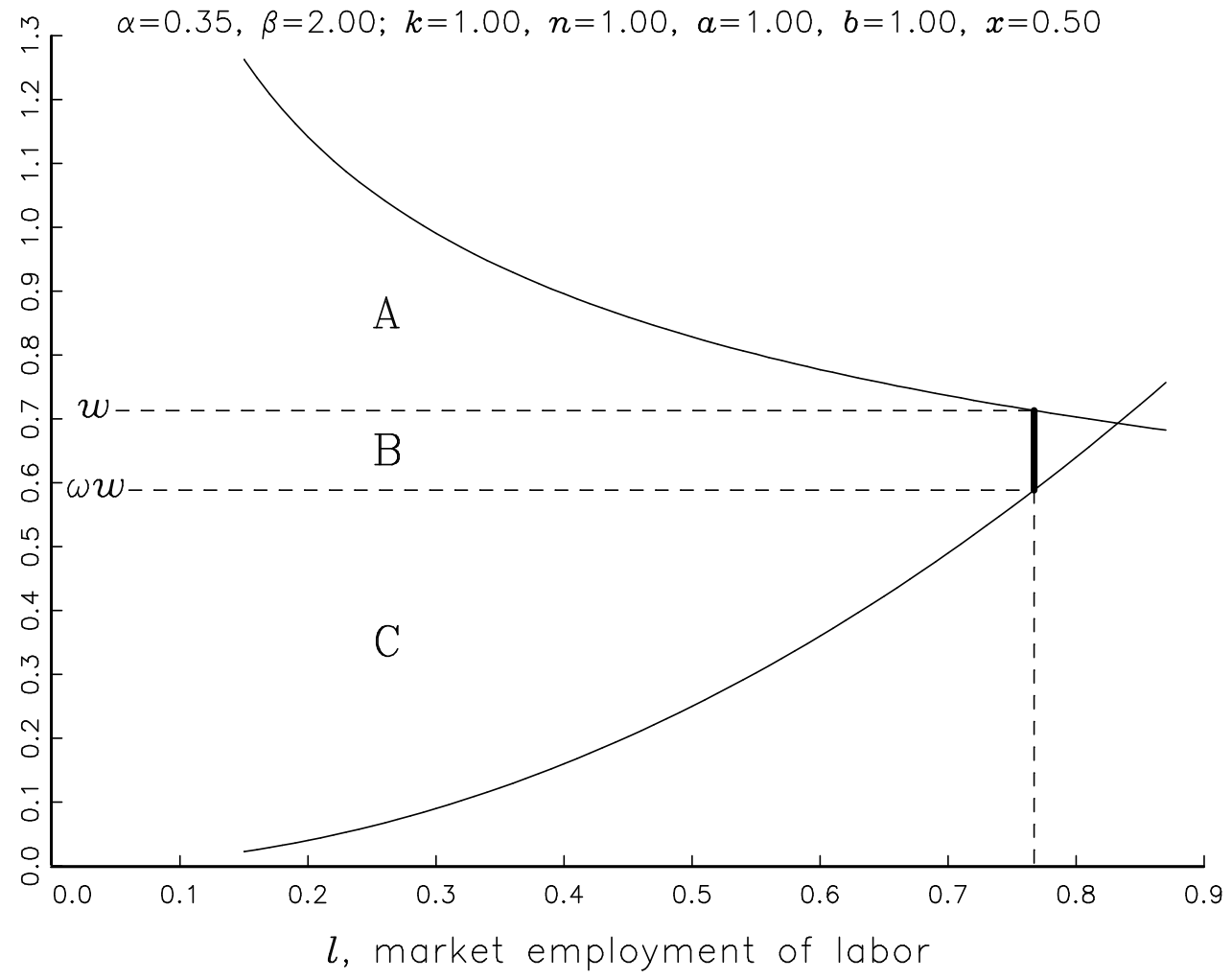

Figure 2. Labor policy and market employment.

The downward sloping line plots $a(1-\alpha)(k)^{\alpha}(a l)^{-\alpha}$, the upward sloping line plots $b(l)^{\beta}$. 


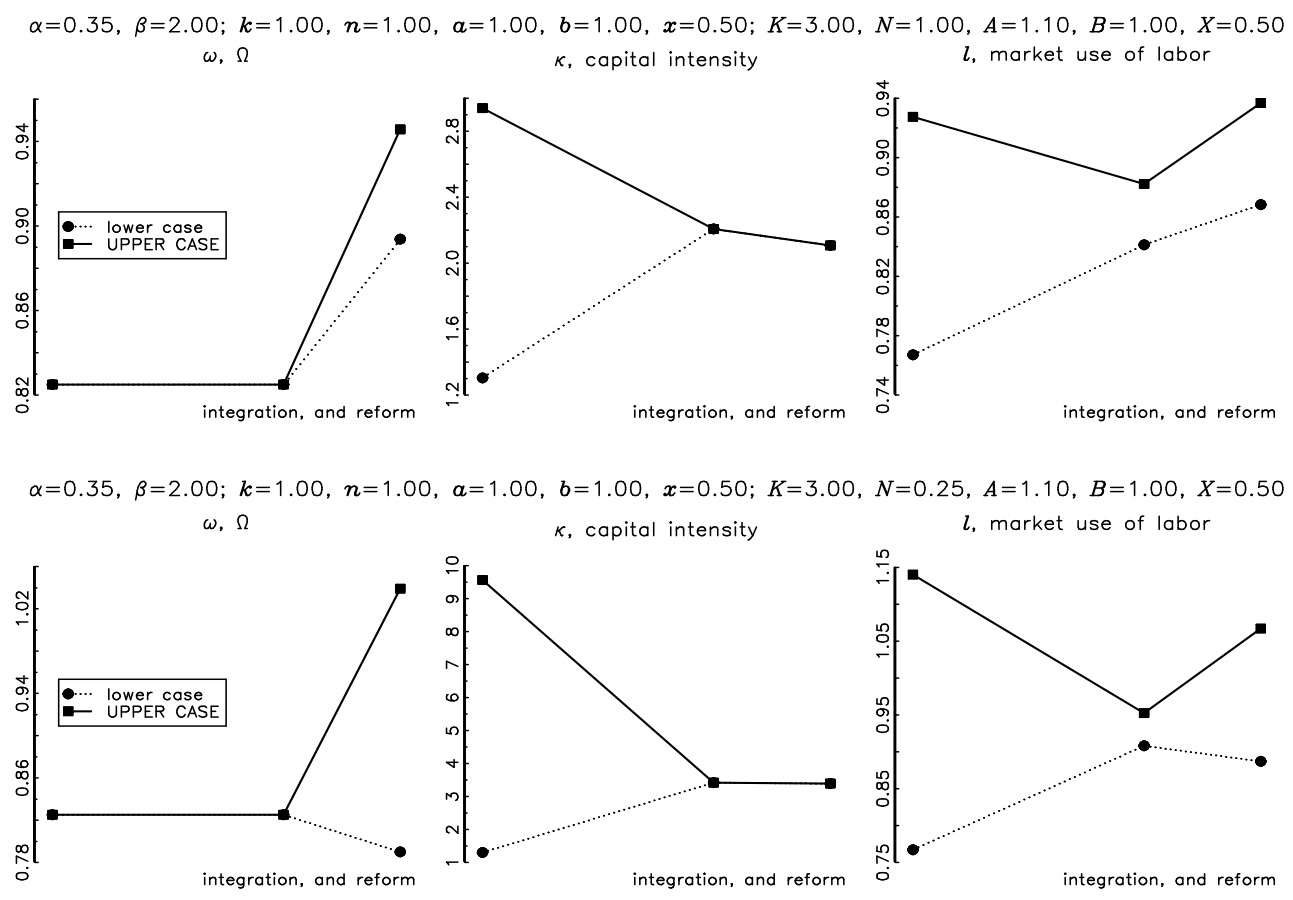

Figure 3. Implications of integration for policy reforms, capital intensity, and employment. 

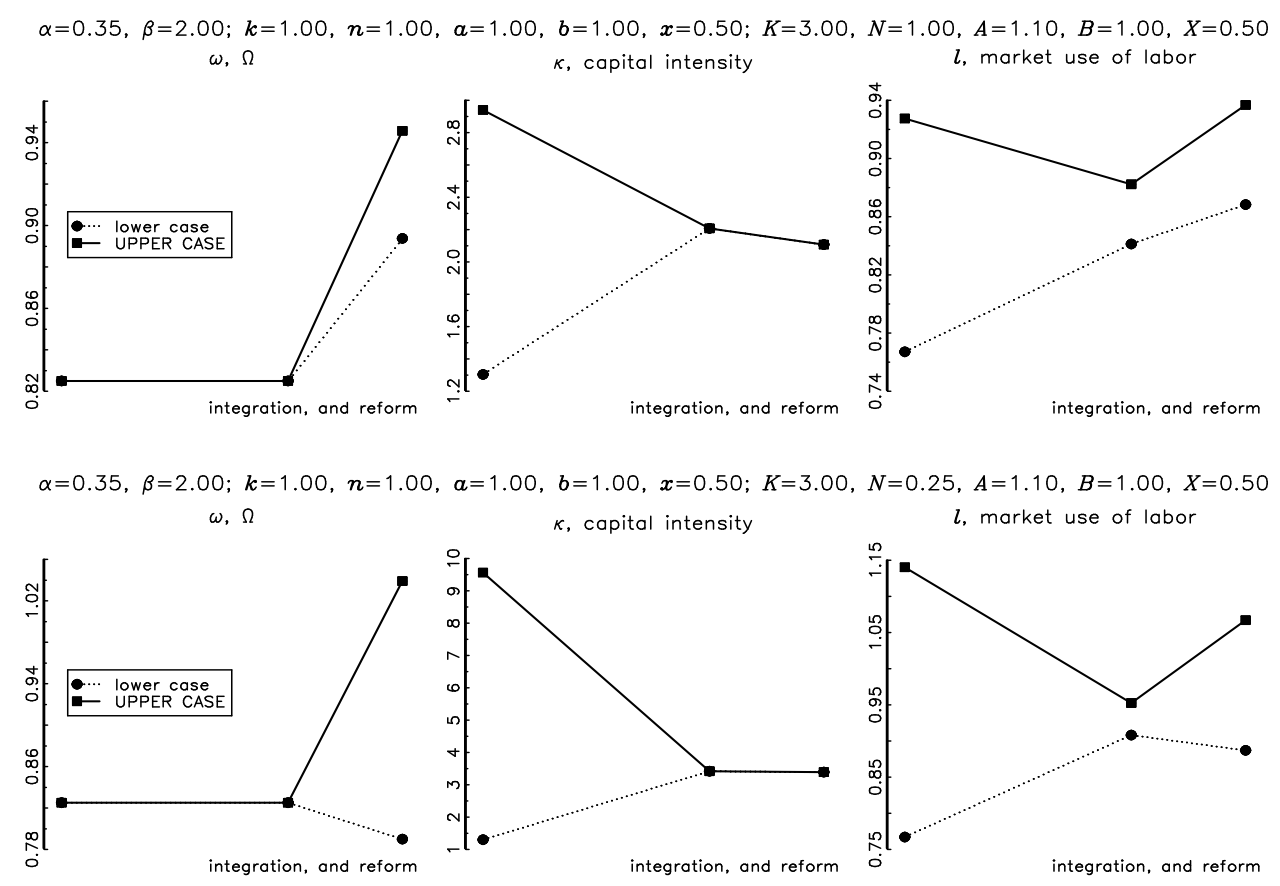

Figure 4. Labor market reforms and capital mobility triggered by integration among heterogeneous countries.

Dots refer to 27 countries featuring all combinations of low, mid-range, and high values of capital $(k)$, size $(n)$, and productivity $(a)$ parameters. Lines join points with the same values of parameters other than the one on the horizontal axis. 


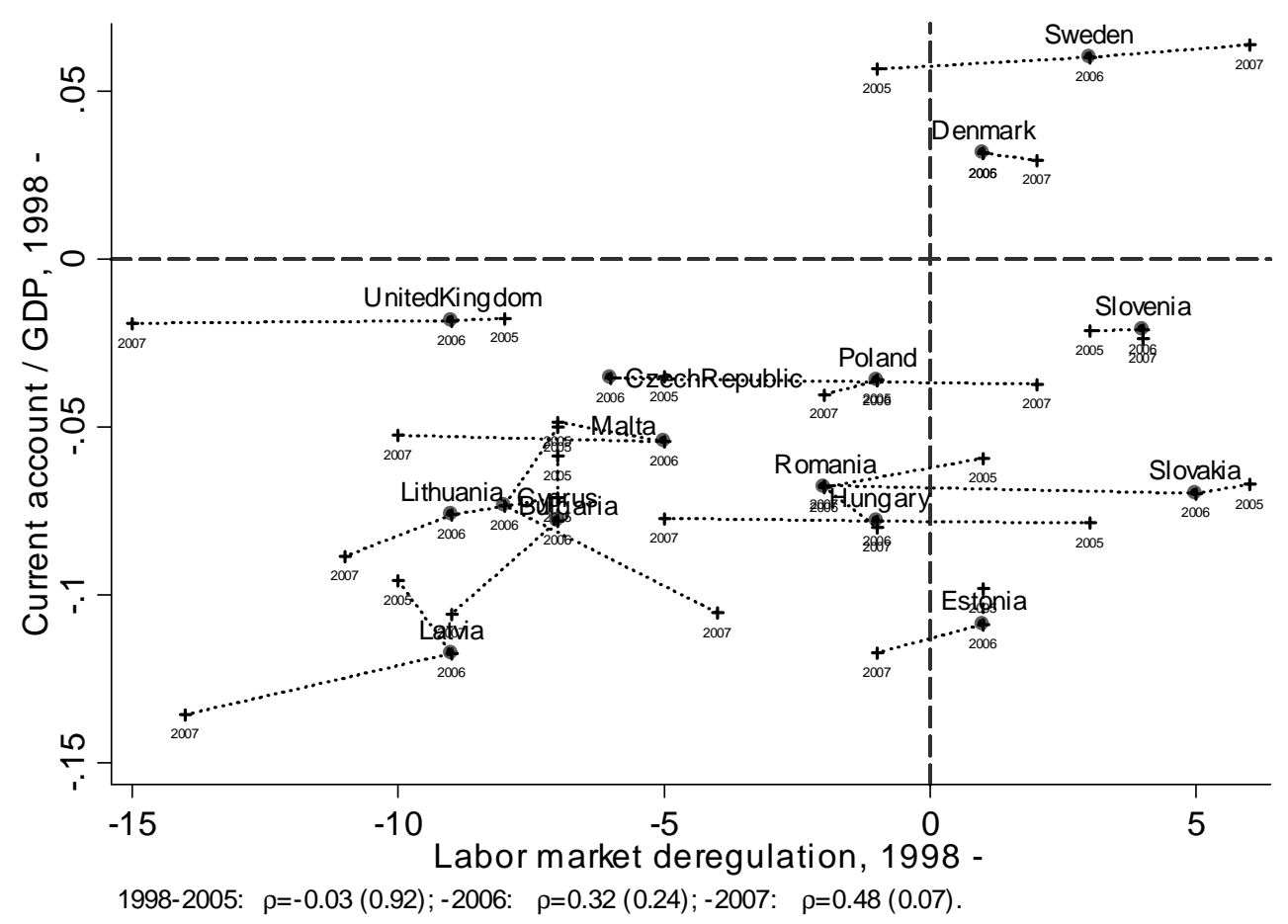

Figure 5. International imbalances and labor market reforms in non-EMU members of the EU.

Definitions and sources as in Figure 1. 


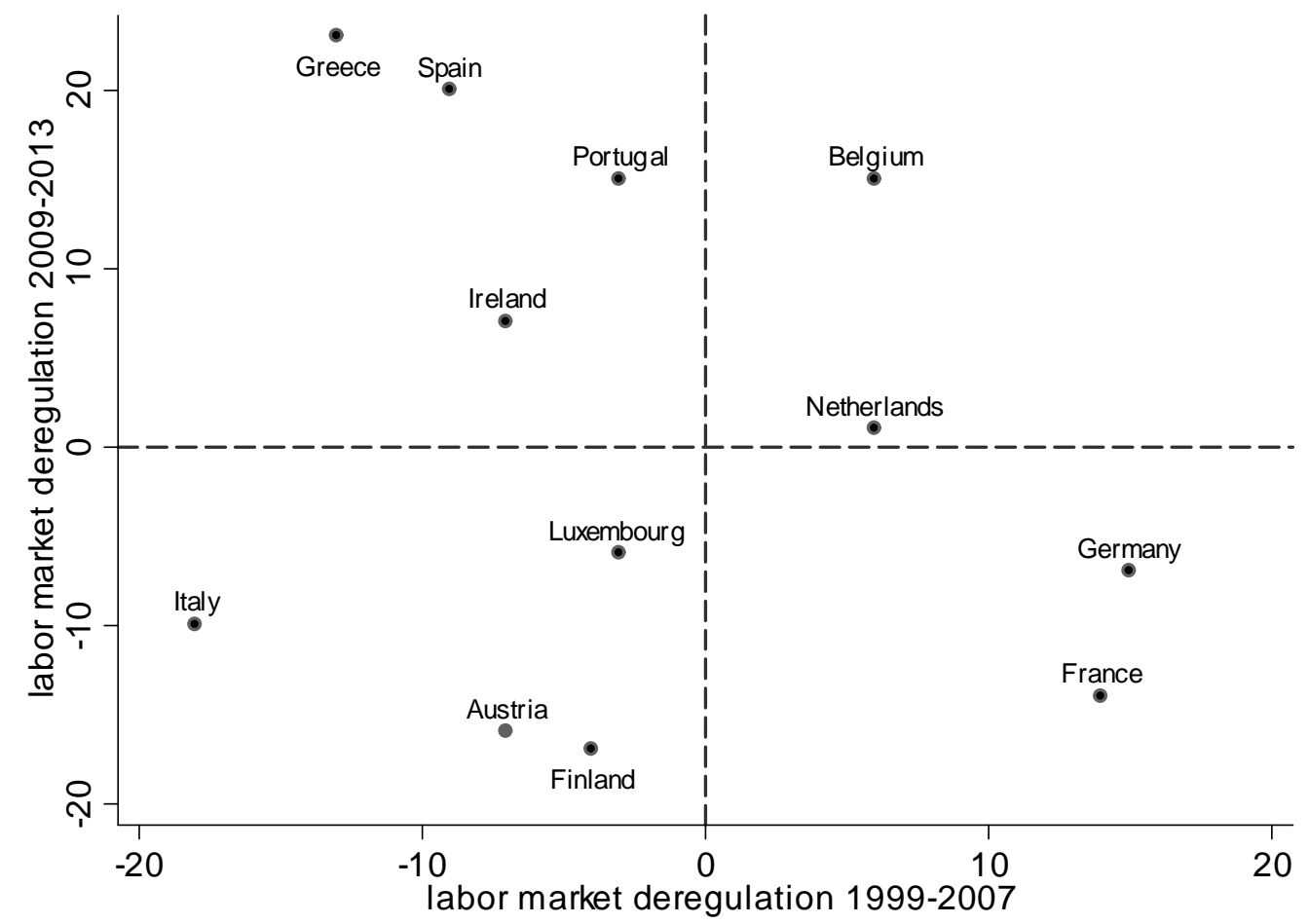

Figure 6. Current accounts and reforms before and after the crisis in EMU.

Definition and source as in Figure 1. 
EMU countries with OECD policy indicators
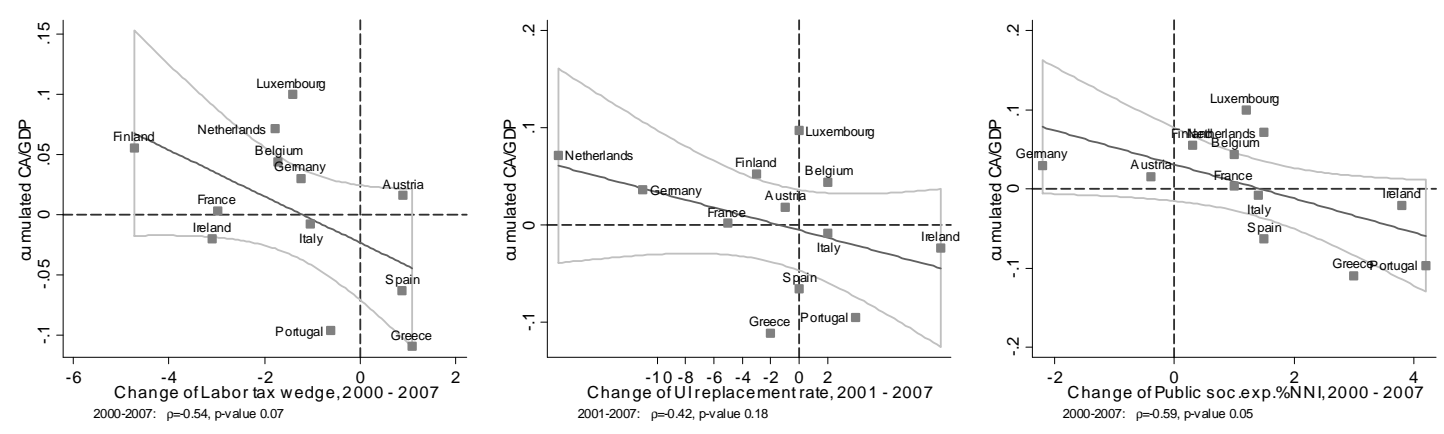

non-EMU countries with OECD policy indicators
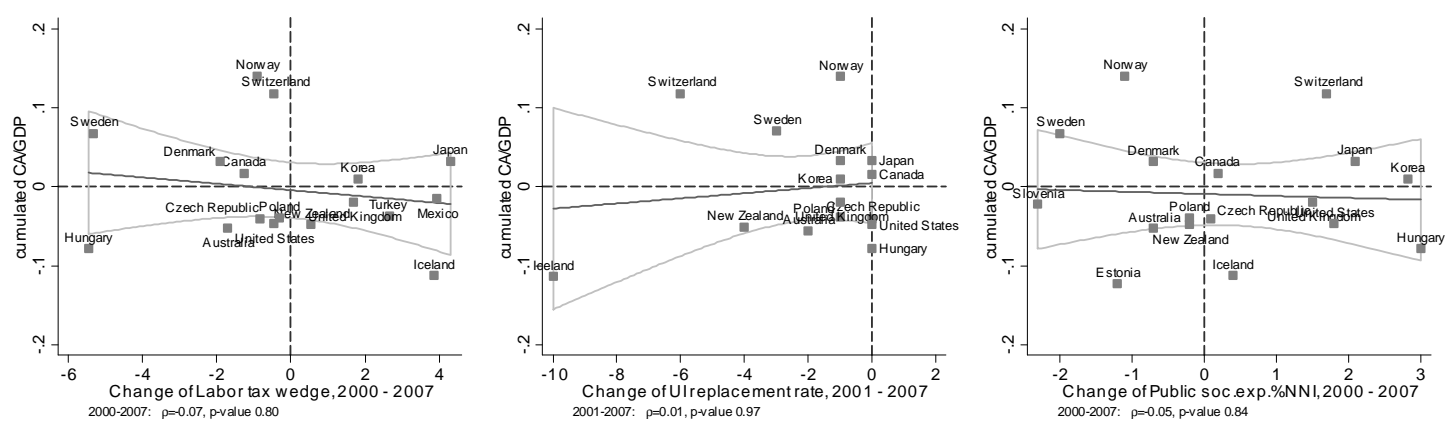

Figure 7. Current accounts and labor policy indicators in and out of EMU.

Cumulative current accounts as percent of cumulated GDP until 2007 (Source: AMECO database), starting from the first year when the labor market policy indicators of which changes are displayed are available (Source: OECD; Definitions: total tax wedge including employer payroll taxes as $\%$ of labor costs, single person at $67 \%$ of average earnings; public social expenditure as \% of NNI; summary measure of gross unemployment benefits entitlements). Linear regressions with 95\% confidence interval and rank correlation (p-value of zero null hypothesis) are displayed in and below each panel. 
EMU countries with OECD policy indicators
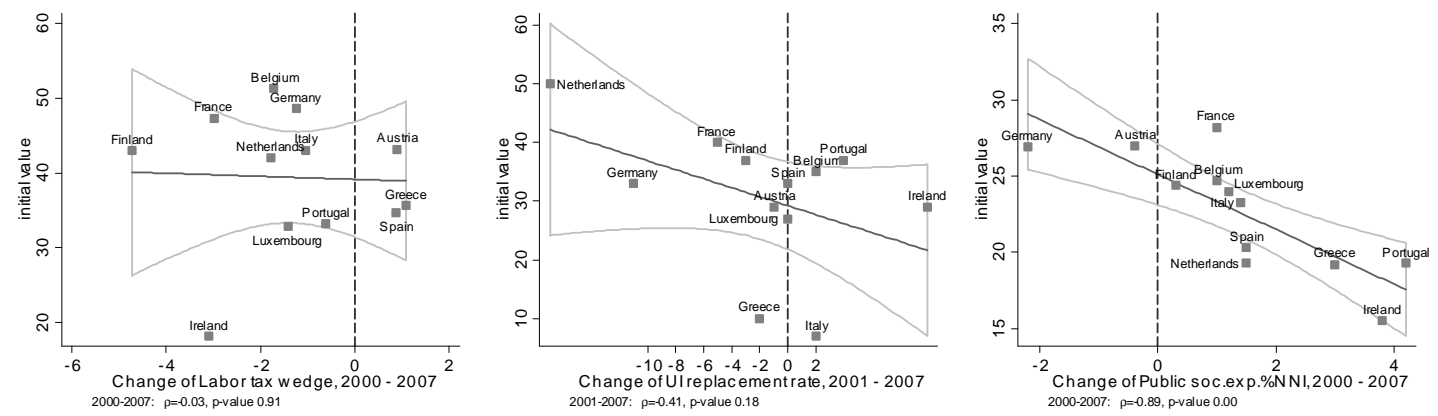

Non-EMU countries with OECD policy indicators
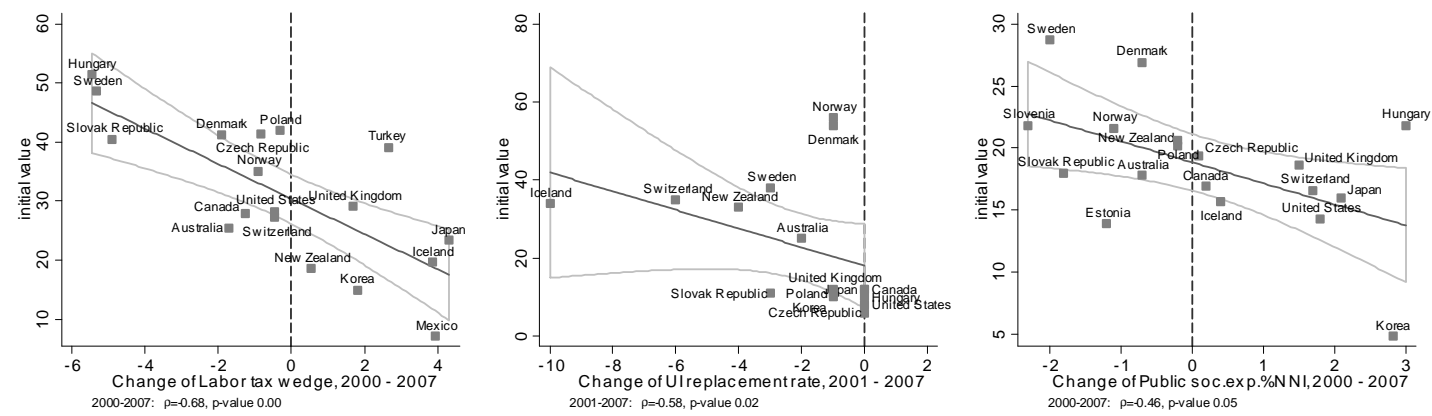

Figure 8. Labor policy convergence in and out of EMU.

Initial level and change until 2007 starting from the first year when the labor market policy indicators are available.Source and definitions as in Figure7. Linear regressions with 95\% confidence interval and rank correlation (p-value of zero null hypothesis) displayed in and below each panel. 

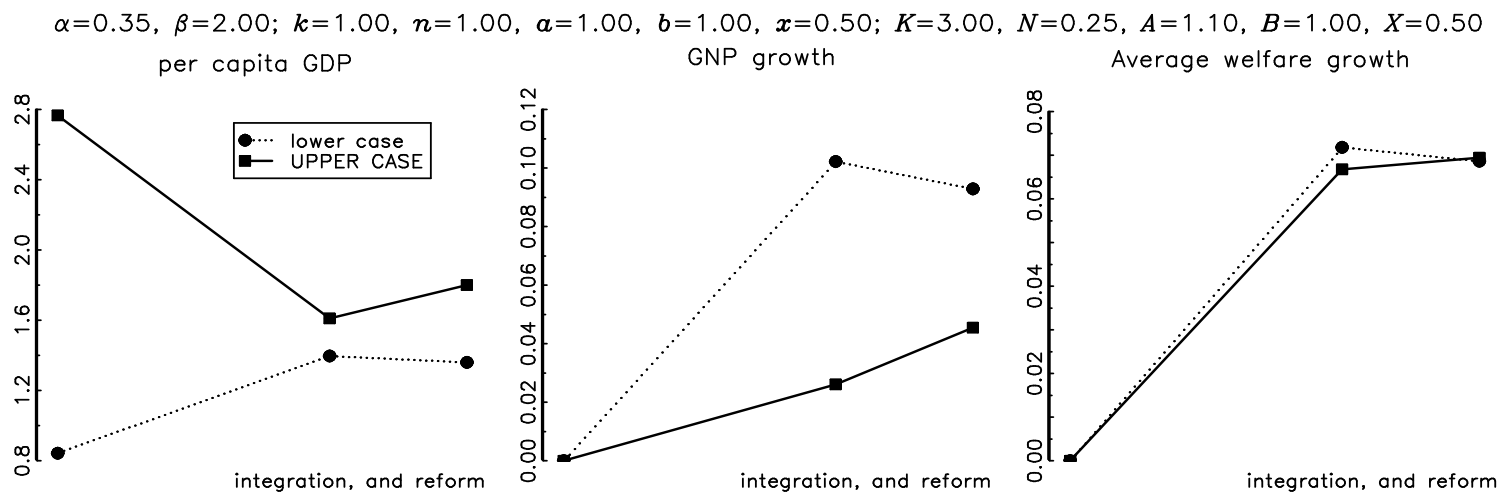

$$
\delta=0.50, \Delta=0.50, \pi=0.66, \quad \Pi=0.66
$$
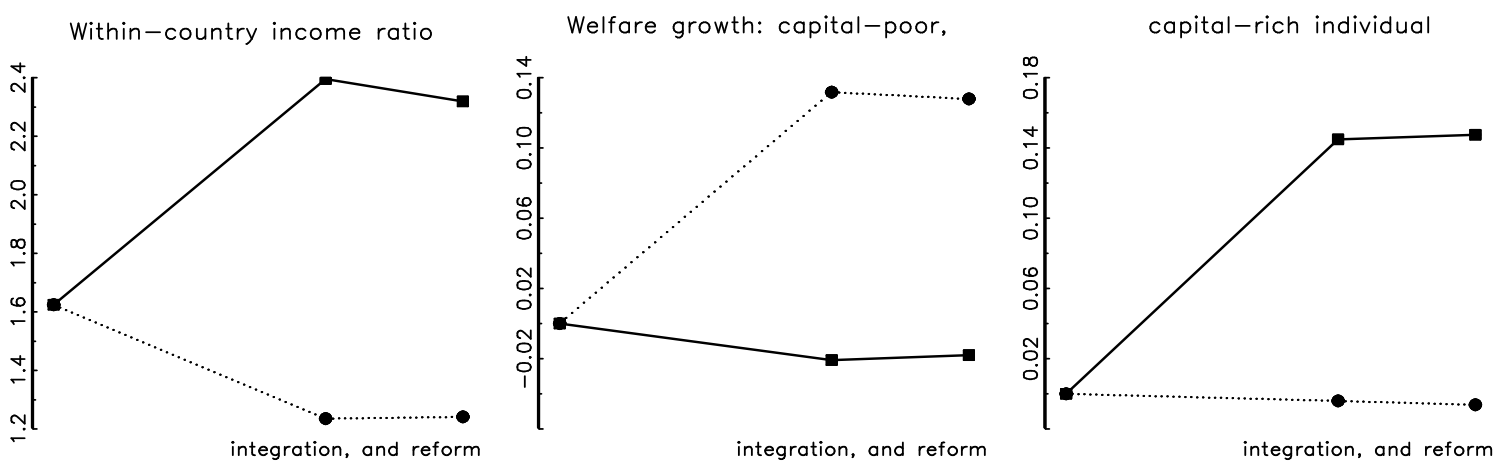

Figure 9. Inequality implications of financial integration.

Countries are parameterized as in the bottom row of Figure 3. Within each country, capital is unevenly distributed across two types of individuals, with the functional forms discussed in the main text and the parameters shown above the bottom row of diagrams. 


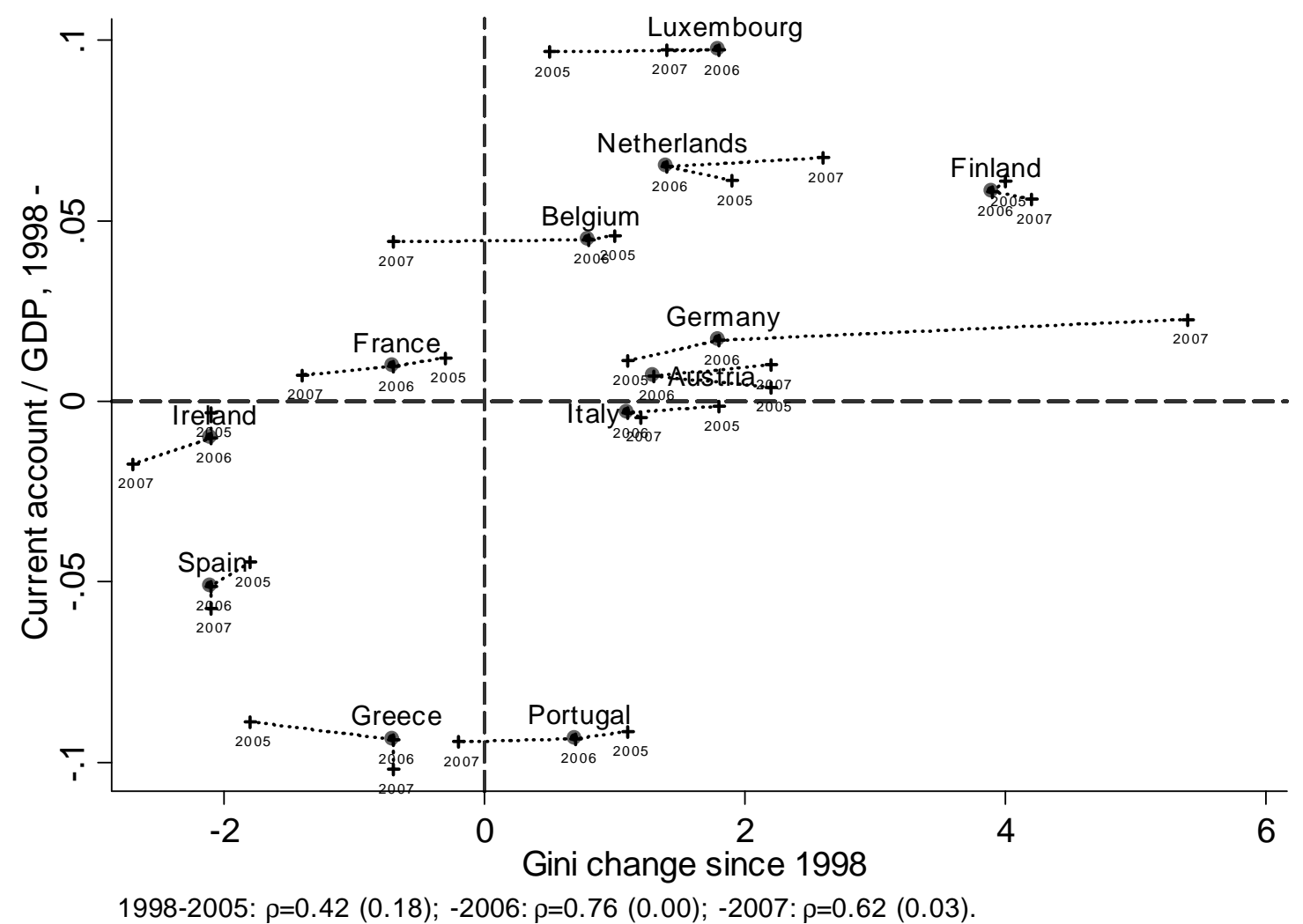

Figure 10. International imbalances and inequality developments in early EMU. Definitions (source): Cumulation of current accounts as a ratio of cumulated GDP (AMECO database); change of the Gini coefficient for equivalized household income (Eurostat) Rank correlation statistics (p-value of zero null hypothesis) are displayed below the figure. 

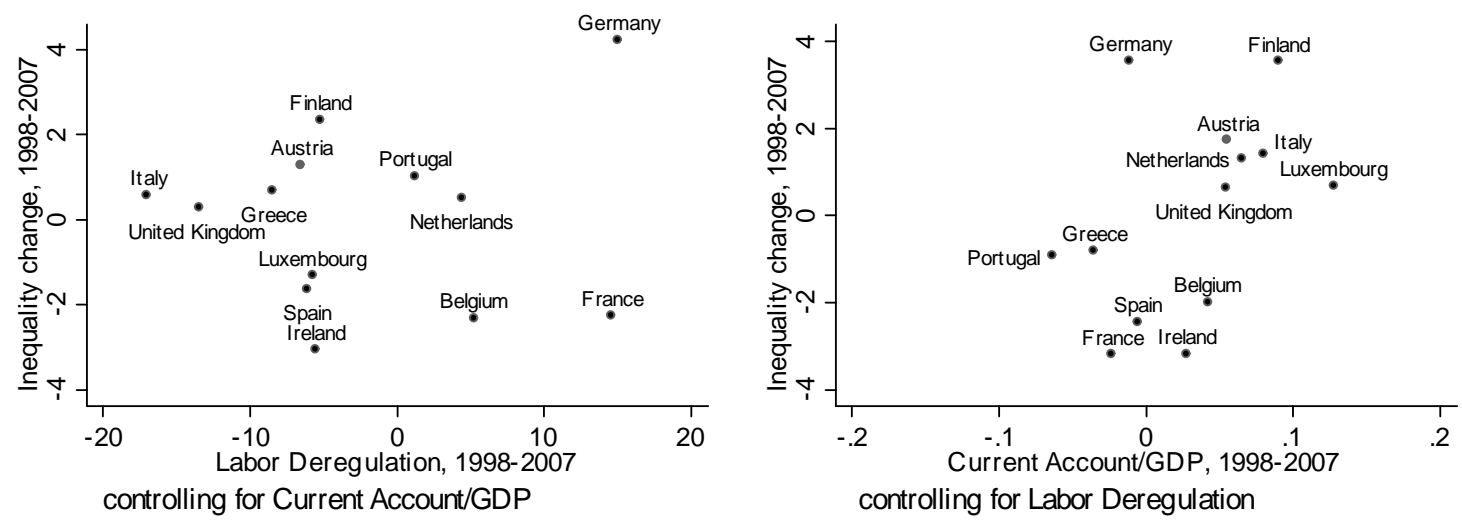

Figure 11. Inequality, reforms, and current accounts in EMU.

Partial correlations of inequality changes with labor market deregulation (t-statistic 0.27) and cumulative current accounts (t-statistic 1.55). Definitions and sources as in Figures 1 and 10 . 